\title{
Construyendo ciudadanía a través de la coeducación
}

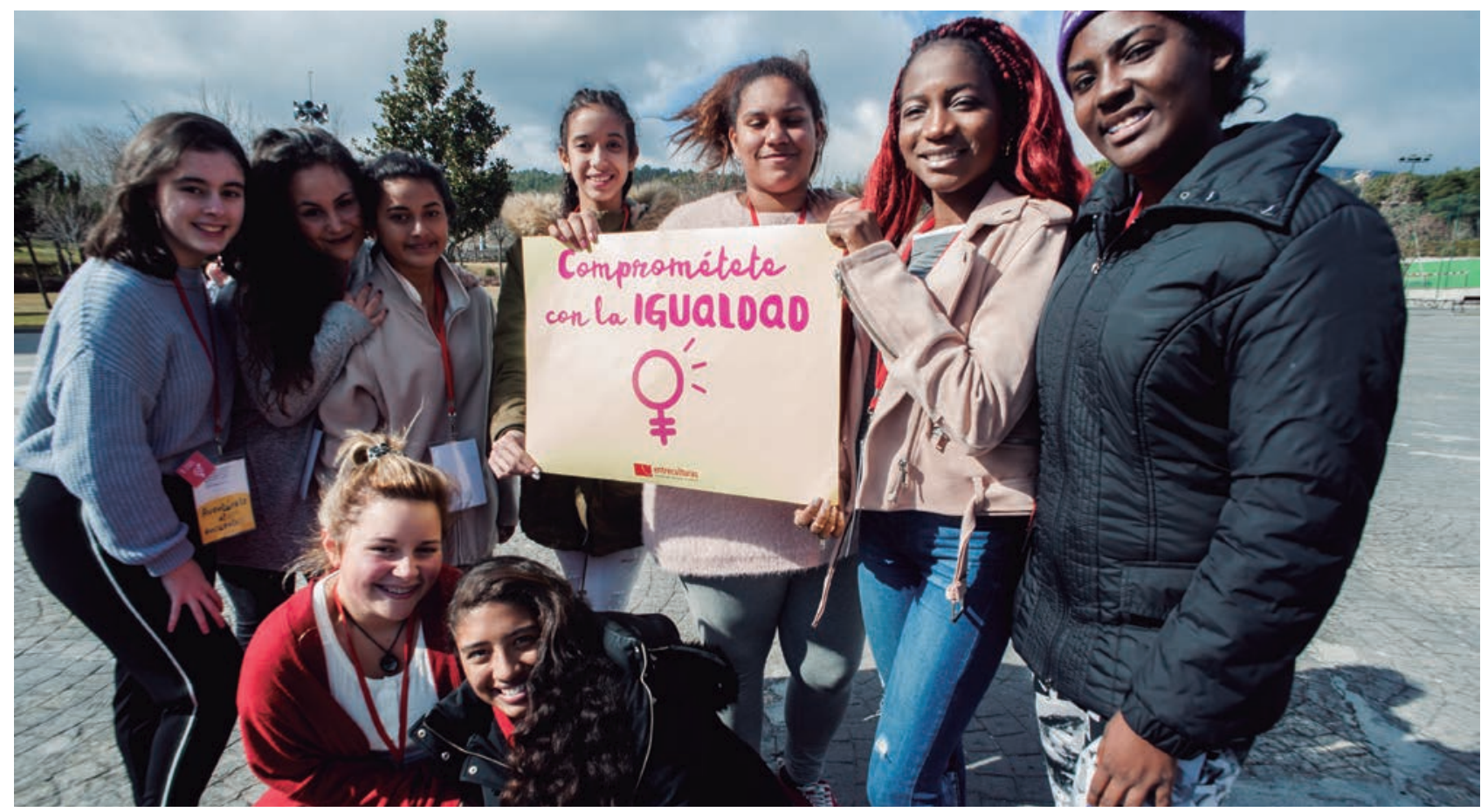

Este artículo aborda la centralidad del compromiso con la igualdad de género en cualquier proceso de educación transformadora y para la ciudadanía global. Fundamentada su importancia, analiza cómo integrar este compromiso de forma transversal en los procesos educativos

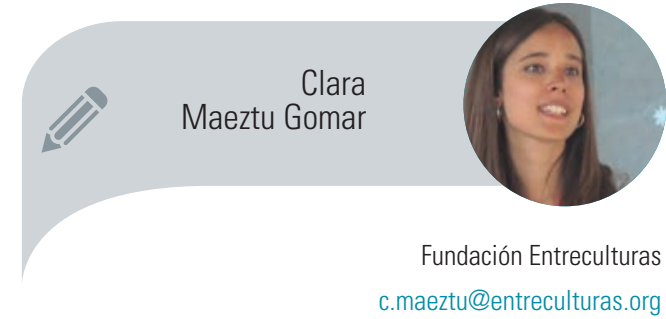

https://www.linkedin.com/in/clara-maeztu-gomar8160a9100/?originalSubdomain=es

www.redec.es a través de la coeducación. Para ello, establece qué entendemos por coeducación y ofrece pautas claras sobre cómo integrar este enfoque desde los diferentes tipos de currículos y ejes educativos de cualquier centro o espacio socioeducativo. 


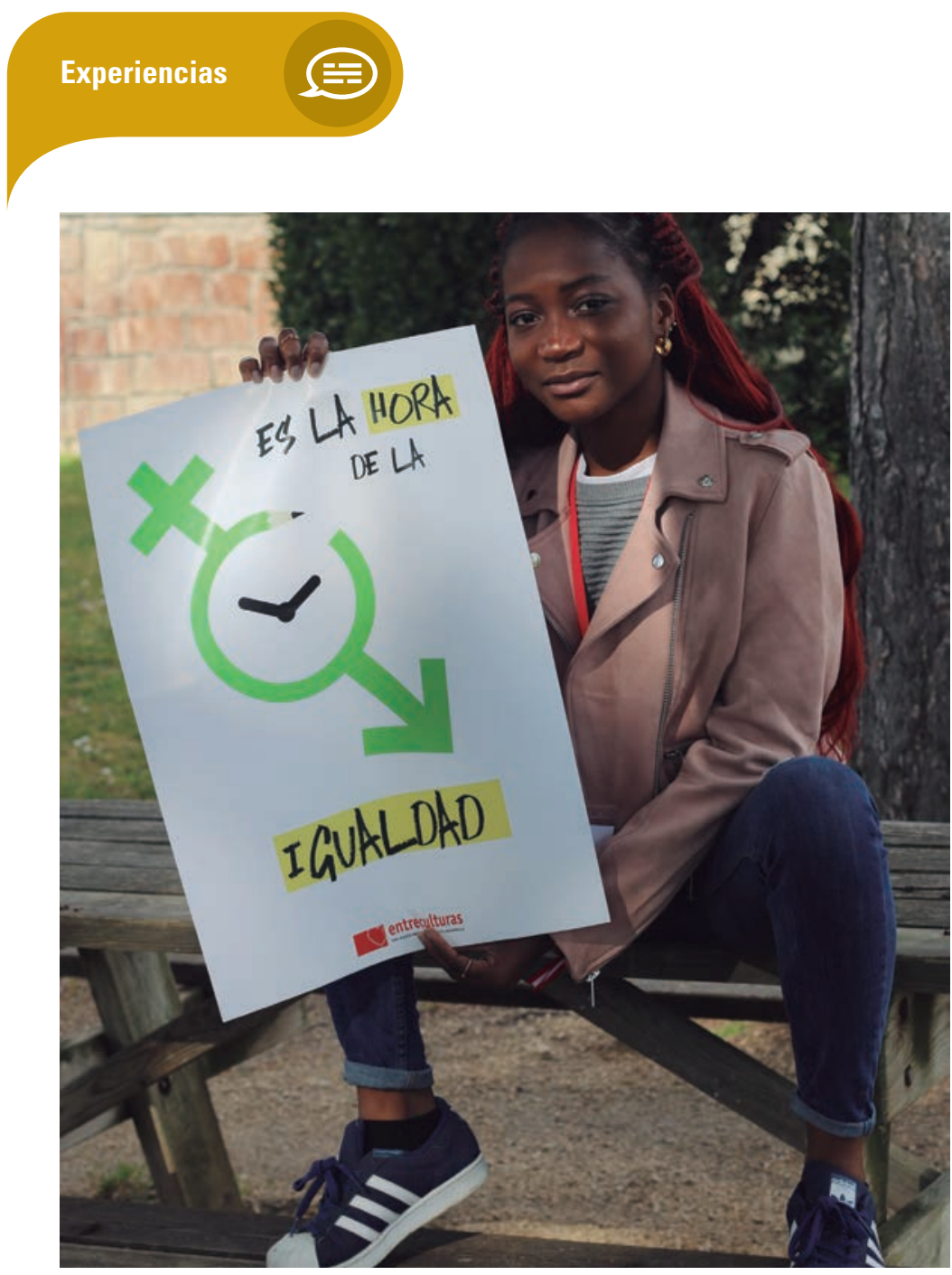

«Yo creo que la principal contribución que puede hacerse para que las mujeres tengamos las mismas posibilidades que los hombres es, sobre todo, educar en igualdad». IRENE, participante del programa de participación juvenil Red Solidaria de Jóvenes, de la Fundación Entreculturas

Desde la práctica totalidad de los ámbitos del conocimiento y la participación ciudadana, llevamos siglos clamando una misma receta para hacer frente a los retos globales de nuestro tiempo: la educación. En las reflexiones y conversaciones personales, grupales y académicas, solemos llegar a la conclusión de que la educación es uno de los ámbitos claves desde los que poner las bases para gestar los procesos de liderazgo ciudadano para la transformación social.

Sin embargo, sería un error conformarnos con esta conclusión, ya que, si hemos identificado en la educación una de las claves para empoderar a la ciudadanía para que haga frente de forma crítica, activa y comprometida a las problemáticas globales que nos interpelan, la siguiente pregunta inevitable debe ser siempre ¿qué tipo de educación debemos promover?
La educación por sí misma no es la clave, ya que una educación que no se revisa y no opta por una finalidad transformadora clara que se refleje de forma transversal en todos los ejes de su enfoque educativo, acabará reproduciendo y transmitiendo las costumbres, creencias y estereotipos que sostienen la desigualdad y la violencia. Nuestra propuesta, por tanto, de educación como respuesta es la Educación para la Ciudadanía Global (EpCG), entendida como una educación para el fortalecimiento de una ciudadanía informada, crítica y comprometida, que conozca la realidad global de su tiempo y protagonice la transformación social y política de la injusticia mediante la lucha contra la desigualdad. A través de la EpCG buscamos promover una ciudadanía interconectada con otras personas y colectivos de todo el mundo que, a través de su interconexión con el ámbito global, sea capaz de construir desde sus entornos locales y el trabajo en red una sociedad transformadora en la que se establezcan relaciones globales justas y equitativas.

Este tipo de educación tiene su reflejo en la esfera internacional en la Agenda 2030 para el Desarrollo Sostenible a través del objetivo de desarrollo sostenible 4, referido la garantizar una educación inclusiva, equitativa y de calidad y, más concretamente, a la meta 4.7 destinada a "promover la educación para el desarrollo sostenible y la adopción de estilos de vida sostenibles, los derechos humanos, la igualdad de género, la promoción de una cultura de paz y no violencia, la ciudadanía mundial y la valoración de la diversidad cultural y de la contribución de la cultura al desarrollo sostenible, entre otros medios". Además, los objetivos de desarrollo sostenible otorgan una atención especial a la lucha contra la violencia y la desigualdad, y sitúan la igualdad de género y el empoderamiento de las mujeres y niñas como un elemento central para lograr la Agenda 2030, concretamente en el ODS 5, pero también en otros como el 10 (reducción de desigualdades), el 11 (ciudades y comunidades sostenibles) o el 16 (paz, justicia e instituciones sólidas). 
La propuesta de este artículo es la de sostener que es imposible desarrollar este modelo de educación transformadora sin situar la igualdad de género a través del enfoque de coeducación en el eje vertebral del mismo.

\section{La igualdad de género y la coeducación como pilares fundamentales de la educación para la ciudadanía global}

El diseño e implementación de procesos educativos que buscan empoderar a la ciudadanía para generar formas de relación más justas, equitativas y sostenibles encuentran en el enfoque de género un elemento fundamental para ser verdaderamente transformadoras. La magnitud, globalidad y consecuencias que tienen la violencia y desigualdad de género en todo el mundo y su centralidad como reto global de nuestro tiempo, provocan que no podamos desarrollar un enfoque educativo que aspire a empoderar a la ciudadanía para que participe de forma activa en la defensa de los derechos humanos y la justicia social, sin que este colocase la igualdad de género en el corazón de su enfoque y práctica educativa. La igualdad de género nos sitúa directamente en el corazón de los derechos humanos y de la justicia social, por lo que su tratamiento, a través del enfoque de la coeducación, es uno de los requisitos imprescindibles de cualquier proceso de EpCG.

A su vez, la educación es un ámbito privilegiado a la hora de abordar la igualdad. La desigualdad entre hombres y mujeres se aprende desde la infancia. Las aulas, como primeros contextos de socialización en las que las niñas y niños aprenden a relacionarse con sus iguales, son un espacio privilegiado a la hora de cuestionar y dejar de reproducir el sistema de creencias, costumbres y prácticas sociales que aprendemos durante el proceso de socialización y que perpetúan las desigualdades, discriminaciones y violencias machistas, en aras de configurar sociedades más igualitarias.

Para asumir la responsabilidad que tiene el sistema educativo en la socializa-

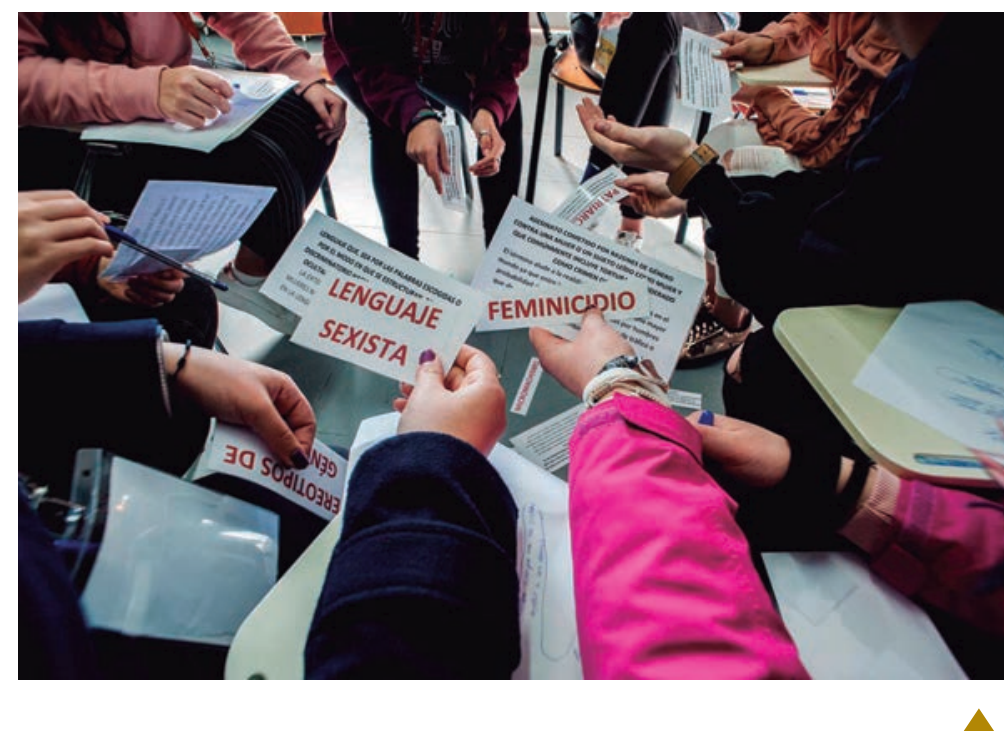

ción de las y los jóvenes y actuar contra la cultura de la desigualdad, es necesario apostar por una educación transformadora que incorpore el enfoque de género en las aulas. De esta forma, la escuela se constituye como un espacio socioeducativo en el que las futuras generaciones aprenden a cuestionar, desde la infancia, las discriminaciones por razón de género, construyendo modelos de relación con los demás y consigo mismas y mismos desde el respeto y la igualdad.

\section{¿Cómo integrar el enfoque de género en los procesos educativos? La coeducación como respuesta}

«Para mí el principal cambio sería la educación. Si recibimos una mala educación, no podemos aportar con grandes ideas y hacer los cambios que queremos». OLGA DOHERTY, joven participante en la Red Generación 21+

A la hora de afrontar el reto de situar la igualdad en el centro de los procesos educativos, nos encontramos con la coeducación como herramienta. La coeducación es el enfoque educativo que integra la perspectiva de género como eje transversal de todos los elementos del proceso de aprendizaje. A diferencia de la escuela mixta, en la que simplemente coexisten niños, niñas y jóvenes en las aulas, la escuela coeducativa reconfigura todos los elementos del proceso de enseñanzaaprendizaje, para que en estos reine el principio de igualdad y no discriminación por razón de género.

De esta manera, la opción por el enfoque de coeducación configura un tipo de educación comprometida con la cons-
Jóvenes realizando un taller sobre coeducación durante el VI Encuentro Global de la Red Solidaria de Jóvenes de la Fundación Entreculturas 
Para comenzar a hacer un diagnóstico sobre cómo se manifiestan las desigualdades de género en el entorno educativo y las posibles acciones que podemos empezar a promover para prevenirlas y actuar sobre ellas, proponemos la siguiente actividad, titulada El mapa de la coeducación. Esta actividad puede realizarse tanto por separado con profesorado, alumnado y familias, como de forma conjunta entre todos los miembros de la comunidad educativa. La actividad consiste en dibujar un mapa del centro educativo y sus alrededores, que refleje todos sus espacios (aulas, patios, baños, salas de profesorado, instalaciones deportivas, pasillos, parques, establecimientos cercanos, etc.). Una vez dibujado el mapa, los y las participantes - divididos en subgrupos 0 en un gran grupo- deberán identificar las desigualdades y discriminaciones por motivos de género que según su experiencia se dan en cada uno de los espacios, escribiendo cada una en una bandera roja pequeña que clavarán con un alfiler en cada espacio. Este ejercicio nos dará de un vistazo una buena perspectiva de las discriminaciones y violencias que se reproducen en nuestros centros y alrededores, promoviendo que los miembros de la comunidad educativa hagan un ejercicio de identificación y autoconciencia sobre las mismas. Puesto el foco en ellas y desterradas por tanto la normalización e invisibilidad que suele reinar en las mismas, el siguiente ejercicio consistirá en identificar las acciones que podríamos poner en marcha sobre cada una, clavadas de nuevo al lado, en este caso en una banderola de color verde. Los y las participantes trasladarán estas propuestas formalmente al equipo directivo, la institución 0 el organismo pertinente, y el mapa se quedará en un espacio visible del centro, como recordatorio de las dinámicas identificadas y las acciones propuestas. A su vez, se establecerán una serie de plazos en los que la comunidad educativa se volverá a reunir para revisar si las propuestas se han puesto en marcha y cómo está yendo su funcionamiento, fomentando el cumplimiento y modificación necesaria de las mismas para que se desarrollen de manera efectiva. trucción de entornos igualitarios y pacíficos, a través de:

7 La adopción de perspectivas críticas sobre las relaciones de género, rechazando prácticas sociales, roles y estereotipos discriminatorios y estereotipados.

त El desarrollo libre e integral de las potencialidades, intereses y capacidades del alumnado, garantizando el disfrute igualitario de sus derechos y oportunidades, así como el desarrollo libre de su identidad.

$\boldsymbol{7}$ La adquisición de herramientas para una convivencia pacífica libre de discriminaciones y violencias.

Para incluir de manera transversal el enfoque de coeducación, debemos analizar cómo integramos la igualdad de género en los tres tipos de currículos:

त Currículo formal: marco de referencia concreto y explícito que orienta el proceso de enseñanza-aprendizaje. Abarca el enfoque pedagógico, los objetivos, contenidos, actividades de aprendizaje, materiales didácticos, criterios de evaluación definidos o asumi- dos por la entidad. ¿Este currículo suele estar diseñado incorporando de manera transversal la perspectiva de género en todos los elementos del proceso de enseñanza-aprendizaje? ¿Incluye objetivos específicos relacionados con la coeducación y la prevención y atención a la discriminación, desigualdad y violencia de género?

$\boldsymbol{\lambda}$ Currículo oculto: interacciones y contenidos no previstos formalmente que se desarrollan en el día a día de los centros. Al no ser explícito, no estar regulado y no ser en muchos casos consciente, es especialmente difícil de detectar lo que dificulta su reconocimiento y la decisión de iniciar un proceso sistemático de observación, autocrítica y transformación. ¿Estimulamos en ambos géneros cualidades como la valentía, la sensibilidad, el liderazgo, la empatía, la escucha, la asertividad, la ternura, la cooperación o el cuidado mutuo? ¿Utilizamos o permitimos expresiones y lenguaje coloquial sexista en clase? ¿Las imágenes, los pósteres, los juguetes y los materiales del centro están estereotipados? ¿Fomentamos la participación activa e igualitaria en los órganos de portavocía del alumnado o la participación en clase? ¿Los roles en clase se reparten de forma equitativa?

त Currículo omitido: temas, contenidos, necesidades, intereses, habilidades y emociones no tratadas durante el proceso de aprendizaje. ¿La contribución de las mujeres a la historia de la Humanidad está suficientemente representada en los contenidos de todas las materias? Los contenidos tratados, ¿incorporan el papel de mujeres y hombres relevantes no estereotipados que puedan servir como referentes para nuestro alumnado? ¿Dejamos de tratar algún tema relevante o de interés del alumnado relacionado con la igualdad de género en las distintas asignaturas, tutorías, etc.? El lenguaje que utilizamos, ¿puede invisibilizar de alguna forma la presencia y aportaciones de las chicas en clase? ¿Tratamos la importancia de los cuidados en clase? 
Para seguir aterrizando la inclusión del enfoque coeducativo, este debe integrarse en los siguientes ejes del proceso de enseñanza-aprendizaje:

خ Organización democrática de la escuela, en la que hombres y mujeres estén representados en condición de igualdad y fomentemos el liderazgo femenino en los espacios de toma de decisiones.

7 Objetivos del currículo con enfoque de género, explícitos y compartidos entre todos los miembros de la comunidad educativa, con mecanismos de evaluación periódica de su consecución.

入 Contenidos y material didáctico: que incluyan el papel de las mujeres en la historia de la Humanidad, con texto y uso de imágenes e ilustraciones en los que no se transmitan roles e imágenes estereotipadas y en los que haya un tratamiento explícito y crítico de temáticas, habilidades y valores relacionados con la igualdad de género. Esto deberá hacerse desde un enfoque centrado en la no discriminación por motivos de género y que integre la mirada interseccional y decolonialista, de manera que abordemos de manera completa el conjunto de violencias y opresiones que supone la discriminación de género.

7 Metodología y organización del aula, de manera que, no solo los contenidos, sino la metodología y actividades a través de las que se imparten, estén diseñados integrando el enfoque de género, de forma que sean inclusivas e incorporen mecanismos de participación igualitaria.

$\boldsymbol{\lambda}$ Las relaciones entre los miembros de la comunidad educativa, con un énfasis especial al refuerzo competencial y la orientación laboral no estereotipada.

$\boldsymbol{\lambda}$ Los espacios del centro, los cuales deben ser disfrutados en condición de igualdad sin discriminaciones, fomentando que sean espacios seguros y acogedores para todos y todas, al tiempo que todos los miembros de la comunidad educativa participan en el mantenimiento de los mismos.

\section{Comprométete con la IGUALDAD}

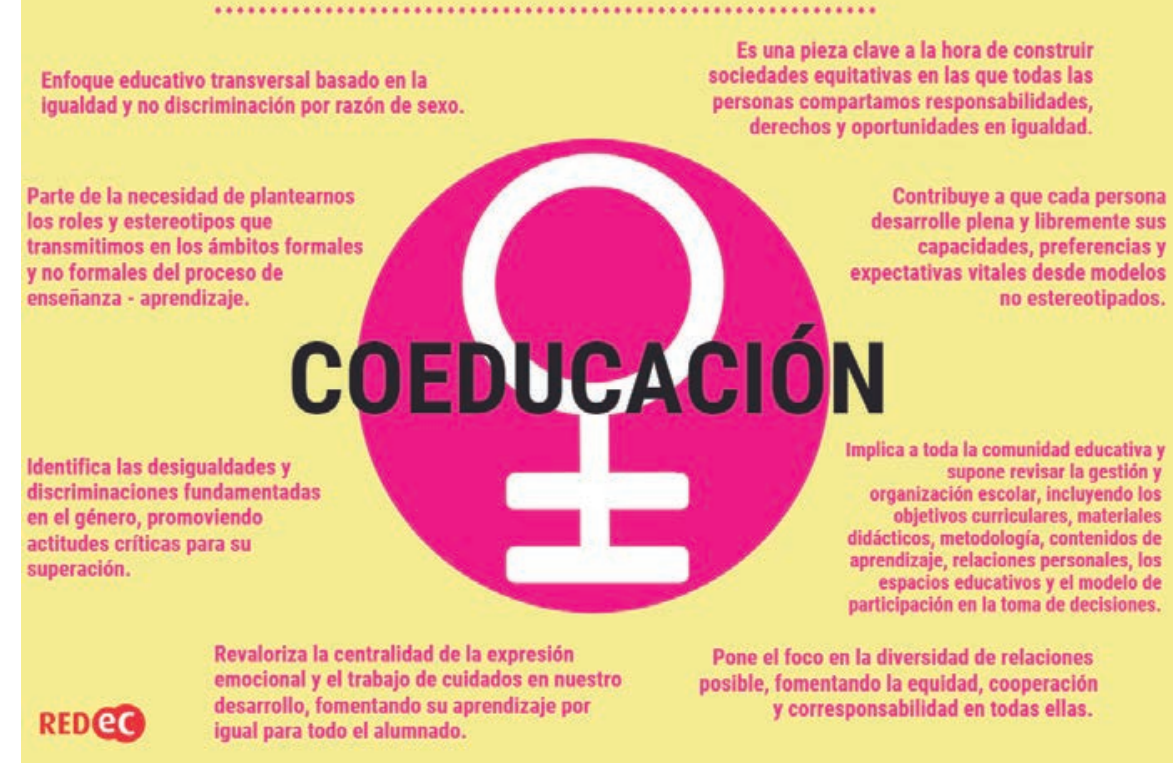

7 El lenguaje: uso de un lenguaje no sexista e inclusivo, que revise las expresiones y formas de dirigirse a todas las personas de la comunidad educativa eliminando sesgos sexistas, al tiempo que incorpora las fórmulas del lenguaje inclusivo.

7 Formación del profesorado permanente, para contribuir a que incorporen conocimientos, herramientas y habilidades para deconstruir sus prácticas educativas, incorporando de manera transversal el enfoque de género en ellas.

7 Protocolos eficaces para prevenir y actuar frente al acoso y la violencia de género en los ámbitos educativos y coordinación intersectorial con los servicios de seguridad, salud, sociales, judiciales y educativos del entorno, dando una respuesta integral tanto a la prevención como a la actuación frente a los casos de discriminación y violencia y los factores comunitarios que los sostienen.

La adopción del enfoque de coeducación requiere avanzar hacia un proceso gradual que incorpore cambios estratégicos integrales en las escuelas y espacios socioeducativos en los tres tipos de currículos y ejes de actuación analizados, incluyendo el enfoque de género en los aspectos formales y no formales del proceso 
de aprendizaje. Para abordar esta transformación con vocación de integralidad de forma efectiva, facilita el proceso realizarlo a través de los siguientes mecanismos:

入 Comprender que es un proceso gradual, que podemos abordar poco a poco, pero a su vez absolutamente necesario para configurar los espacios educativos como ámbitos seguros, inclusivos y transformadores.

入 Asumir el enfoque coeducativo como proyecto educativo de centro, en el que esté involucrado todo el claustro y equipo directivo.

خ Articular procesos de implicación y participación de toda la comunidad educativa, a través de procesos de formación, diálogo y participación activa de los agentes comunitarios, familias y alumnado, junto al equipo educativo.

入 Atender de manera especial a la primera infancia y los primeros ciclos educativos, donde empiezan a gestarse los cimientos de las identidades y roles estereotipados.

7 Buscar medios en los marcos legislativos y políticas ya establecidos, al tiempo que contribuimos activamente en procesos de incidencia para subsanar las limitaciones de los ya existentes.

\section{Conclusiones: coeducación, el enfoque educativo inaplazable}

Como hemos visto durante el desarrollo de este artículo, la igualdad de género y la coeducación como enfoque para promoverla, deben ser elementos estraté-

\section{DRRR SABER MÁS}

BLAS GARCíA, A. DE (2018). 71 propuestas para educar con perspectiva de género. Madrid: Fuhem.

García Fernández, J., y Maeztu Gomar, C. (2017). Un Mundo de Encuentros. Málaga: Fundación Entreculturas. Recuperado de https://www.entreculturas.org/es/publicaciones/un-mundo-deencuentros

García, A. (2009). Género y desarrollo humano: una relación imprescindible. Entreculturas, InteRed, Ayuda en Acción. gicos centrales de cualquier modelo educativo. Su integración, aunque compleja y ambiciosa, nos permite expresar en la práctica un verdadero compromiso con la igualdad y constituye la máxima expresión de coherencia para una escuela que quiera considerarse transformadora.

La magnitud de las consecuencias de la desigualdad y violencia de género a nivel global nos urge a integrar este enfoque de manera inaplazable, ya que no hay motivos que justifiquen seguir procrastinando la apuesta explícita por el mismo. Como alivio al trabajo que esto supone, contamos con mucha literatura pedagógica y la guía de innumerables procesos y buenas prácticas educativas, que nos facilitan y alumbran el camino. La fuerza de las razones que nos impulsan a apostar por este enfoque también son el mejor refugio ante cualquier momento de duda y dificultad que podamos encontrarnos.

Nos encontramos, por todo lo dicho, ante una revolución educativa improrrogable; aquella que nos da la oportunidad de trabajar juntos y juntas en el reto de configurar los espacios socioeducativos como ámbitos clave en la construcción de sociedades más igualitarias, libres de discriminaciones y violencias, permitiéndonos atender mejor las necesidades integrales de nuestro alumnado. Toda la comunidad educativa crecerá por el camino de hacer de la igualdad de género, a través de la coeducación, no solo un valor o una aspiración, sino una experiencia vivida. Asumamos, pues, sin más demora este necesario reto que, desde todo los ámbitos de la sociedad, lleva siglos interpelándonos •

HEMOS HABLADO DE

Educación global; coeducación;
igualdad de oportunidades; géne

Este artículo fue solicitado por PADRES Y MAESTROS en mayo de 2019, revisado y aceptado en octubre de 2019. 